\title{
Calcium Channel Opening Rather than the Release of ATP Causes the Apoptosis of Osteoblasts Induced by Overloaded Mechanical Stimulation
}

\author{
Lu Liu $^{\mathrm{a}}$ Hui Lic Ying Cui ${ }^{\mathrm{a}}$ Ruixin Li ${ }^{\mathrm{b}}$ Fan Meng ${ }^{\mathrm{a}} \quad$ Zi Ye ${ }^{\mathrm{a}} \quad$ Xizheng Zhang $^{\mathrm{b}}$ \\ aLogistical College of Chinese People's Armed Police Forces, Tianjin, bInstitute of Medical Equipment of \\ the Academy of Military Medical Sciences, Tianjin, 'Tongchuan Detachment, Shaanxi Corps of \\ Chinese People's Armed Police Forces, Tongchuan, China
}

\section{Key Words}

Osteoblast • Overloading • Calcium channel $•$ ATP $•$ Cell apoptosis

\begin{abstract}
Background: Stress fracture is one of the most common overuse injuries in athletes. Overloaded mechanical stimulation is an important factor affecting stress fractures, but the mechanism is unclear. Methods: MC3T3-E1 cells and a polycaprolactone (PCL) scaffold were co-cultured, and finite element analysis (FEA) was used to analyze the load-carrying capability. Cell proliferation was investigated with CCK-8 assays. An alkaline phosphatase (AKP) activity assay was used to evaluate cell differentiation. Cell apoptosis was analyzed using Hoechst/ PI double-labeling, Caspase-3 activity and lactate dehydrogenase (LDH) activity assays. Realtime PCR and Western blotting were used to examine the gene and protein expression, respectively, of Caspase-3 and Caspase-9. Assays of the intracellular calcium with fluorescent probe technique and extracellular ATP with fluorometric assay kit were used to analyze the changes in the intracellular calcium concentration induced by calcium channel opening and the release of ATP, respectively, at different operation times. Results: When the apparent strain reached $10000 \mu \varepsilon$, the strain scope of fiber at levels greater than $4000 \mu \varepsilon$ was $60 \%$. Overloading for 4 days and operation times of $0.5 \mathrm{~h}$ and $2 \mathrm{~h}$ increased the cell number and AKP secretion. However, apoptosis genes were activated at the same time, and the operation time of $2 \mathrm{~h}$ had a significantly greater effect than $0.5 \mathrm{~h}$. At 8 days, the cell numbers were greater for the operation time of $0.5 \mathrm{~h}$ than for $2 \mathrm{~h}$, and the 2-h groups had the fastest apoptosis rate. Overloading for 1 day increased intracellular calcium levels and ATP release. The increase in intracellular calcium could be blocked by the addition of $\mathrm{N}$-ethylmaleimide (NEM) or Hank's medium. Overloading for 8 days increased intracellular calcium levels but decreased extracellular ATP, and verapamil blocked the increase in intracellular calcium. Conclusion: We found that a simultaneous 'double effect' on osteoblasts was induced by overloading, which promoted cell proliferation, differentiation and apoptosis. Short-term overloading could open the cell membrane calcium channels and release calcium stores to elevate intracellular calcium L. Liu and H. Li contributed equally to this work.




\section{Cellular Physiology Cell Physiol Biochem 2017;42:441-454

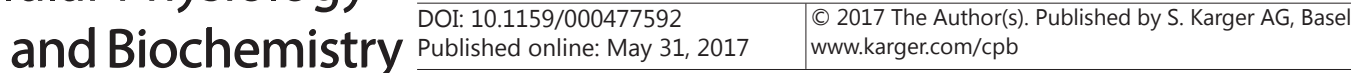

Liu et al.: Overloaded Mechanical Stimulation Causes the Apoptosis of Osteoblasts

levels, thereby promoting the proliferation and differentiation of cells to a greater extent than the effect of apoptosis. For long-term overloading, calcium channel opening in the membrane could lead to overloading of intracellular calcium levels, inducing an apoptosis effect that is greater than the effect on proliferation and differentiation.

(C) 2017 The Author(s)

Published by S. Karger AG, Basel

\section{Introduction}

Stress fractures caused by repeated and continuous force and long-term accumulation of damage are one of the most common ailments in the infantry. Stress fractures are also one of the most common overuse injuries in athletes and account for up to $20 \%$ of all injuries presented to sports medicine clinics [1]. Previous studies have found that stress fractures are associated with bone remodeling activities, including bone formation and bone resorption. Both osteoblasts and osteoclasts are involved in this process [2].

Mechanical stimulation plays an important role in bone remodeling, which is balanced between bone formation and bone resorption at physiological loading levels (200-4000 $\mu \varepsilon)$. Mechanical stimulation can promote osteoblast differentiation and suppress osteoclast differentiation, resulting in increased bone mass and strength. These have great significance for bone repair in patients with fractures and in menopausal women for osteoporosis prevention [3-6]. Bones experience overloaded mechanical stimulation when the strain is greater than $5000 \mu \varepsilon$. At this time, the mechanical stimulation inhibits the activity and function of bone and even causes apoptosis in bone tissues [7, 8]. However, few in vitro experiments have studied the osteoblast apoptosis induced by overloaded mechanical stimulation.

Apoptosis, or programmed cell death, is an important component of the homeostasis that regulates the body's growth and development. The mechanisms of cell apoptosis are divided into a mitochondrial pathway, an endoplasmic reticulum pathway and a death receptor pathway [9-12]. The mitochondrial apoptosis pathway is thought to be caused by calcium overloading. Calcium is a vital osteoblast regulator, and intracellular calcium is clearly associated with the regulation of osteoblast functions. Mechanical stimulation promotes osteoblast proliferation and differentiation by elevating intracellular calcium levels and activating calmodulin (CaM) and the expression of CaMKII and c-fos [13]. Additionally, a large-magnitude $(12 \%)$ cyclic stretch induced $\mathrm{Ca}^{2+}$ influx, which activates reactive oxygen species generation and then the ASK1-JNK/p38 pathways, contributing to osteoblast apoptosis [14].

Adenosine triphosphate (ATP) is closely connected to increases in intracellular calcium. Studies have found that the increased intracellular calcium caused by mechanical stimulation is a second messenger that promotes cellular ATP secretion $[15,16]$. Through a receptor on cell membranes, extracellular ATP leads to increased calcium release from stores, and mechanical stimulation increases cell proliferation and differentiation. In contrast, stimulation of the P2X7 receptors for ATP leads to an elevation of intracellular calcium and increases cell death [17]. However, whether the changes in ATP and intracellular calcium induced by overloaded mechanical stimulation can lead to cell apoptosis has not been proven.

From the point of view of bionics, it might be better to grow osteoblasts in a threedimensional scaffold to copy the environment of the human body. A series of studies found that cells in a two-dimensional plastic culture plate had different biological effects than those in three-dimensional scaffolds. Our experiment used three-dimensional printed polycaprolactone (PCL) scaffolds as described by Sung et al. and Kumar et al. [18, 19]. The co-culture of MC3T3-E1 cells and the scaffold promotes osteoblast proliferation and differentiation in the stress load and circulatory perfusion biological reactor, as described by Liu et al. Subsequently, bone will form [20]. The stress load and circulatory perfusion biological reactor can copy the environment of bone tissue effectively, and it provides a relative measure of the actual force experienced by cells. In this experiment, MC3T3-E1 cells and a scaffold were co-cultured until the scaffold was covered by cells, which were then 


\section{Cellular Physiology Cell Physiol Biochem 2017;42:441-454

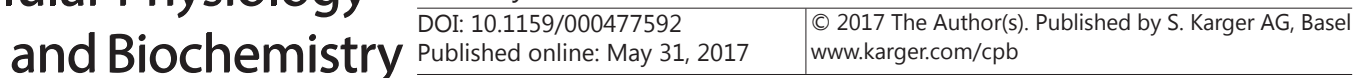

Liu et al.: Overloaded Mechanical Stimulation Causes the Apoptosis of Osteoblasts

loaded into the stress load and circulatory perfusion biological reactor. We demonstrated the effects of overloaded mechanical stimulation for different durations and operation times on osteoblast apoptosis by measuring cell apoptosis-related factors, such as the concentrations of relevant proteins and RNA and the activity of Caspase- 3 and Caspase- 9 , to explore the role of calcium and ATP in osteoblast apoptosis and to provide evidence to elucidate the mechanism of stress fractures.

\section{Materials and Methods}

\section{Three-dimensional culture with MC3T3-E1}

MC3T3-E1 cells, a mouse monoclonal pre-osteoblastic cell line, were seeded on 3-D printed PCL scaffolds as previously described [20] at a density of $2 \times 10^{6} / \mathrm{mL}$. After $4 \mathrm{~h}, 10 \mathrm{~mL}$ of medium (L-DMEM with $10 \%$ fetal bovine serum plus $1 \%$ antibiotics supplemented with $250 \mu \mathrm{M}$ ascorbic acid-2-phosphate (Sigma), $100 \mathrm{nM}$ dexamethasone (Sigma), $10 \mathrm{mM}$ ß-glycerol-phosphate (Sigma)) was added to the cell-scaffold constructs [21] For the 14 days of co-culture, all incubations were performed at $37^{\circ} \mathrm{C}$ in a humidified atmosphere of $5 \% \mathrm{CO}_{2}$, and the medium was changed every 2 days. A preliminary study showed that the cells could grow well on a PCL scaffold. The co-cultured cells and PCL scaffold were placed in the loading instrument, with the stress set at $10000 \mu \varepsilon$ and $1 \mathrm{~Hz}$. A group with no mechanical loading and the same conditions was used as the control group.

\section{FEM analysis}

FEM analysis was used to analyze the load-carrying capability for mechanical loads of 5000, 7500, and 10000 microstrain $(\mu \varepsilon)$. Three-dimensional inverse reconstruction software Geomagic (Geomagic, USA) was used to find the non-uniform rational basis spine (Nurbs) surface. The actual strain distribution of the PCL scaffold was determined by the analysis.

\section{Hoechst/PI double-labeling assays}

Loaded cells and control cells were placed in Eppendorf (EP) tubes and washed with PBS three times. To each tube, a solution of $200 \mu \mathrm{L}$ PBS, $2 \mu \mathrm{L}$ Hoechst-33342 (Enzyme-linked, China) and $2 \mu \mathrm{L}$ propidium iodide (PI, Enzyme-linked, China) was added. After incubation for $4{ }^{\circ} \mathrm{C}$ and $15 \mathrm{~min}$ in the dark, the cells were removed, placed in a new EP tube, and washed with PBS twice. Cells were removed and observed under a fluorescence microscope.

\section{Cell Counting Kit-8 assays}

The MC3T3-E1 cell proliferation was investigated using a Cell Counting Kit-8 assay (CCK-8 Boster, China) according to the manufacturer's instructions. Cells were placed in a 24 -well plate after mechanical loading, shaken for $10 \mathrm{~min}$ and incubated for $4 \mathrm{~h}$ after the addition of $540 \mu \mathrm{L}$ medium and $60 \mu \mathrm{L}$ CCK 8 reagent. The supernatant was then added to 96-well plates with a total volume of $200 \mu \mathrm{L}$ in each well and measured in a Microplate Reader (TECAN, Austria) at a wavelength of $450 \mathrm{~nm}$.

AKP activity assays

The medium was removed and centrifuged at $14,000 \times \mathrm{g}$ for $10 \mathrm{~min}$ at $4{ }^{\circ} \mathrm{C}$. The clear supernatant was used for an alkaline phosphatase (AKP) activity assay using an AKP activity assay kit and measured in a Microplate Reader (TECAN, Austria) at a wavelength of $520 \mathrm{~nm}$.

\section{Caspase-3 activity assays}

Cell apoptosis was measured using a Caspase-3 activity kit (Jiancheng, China). Cells of each group were placed in an EP tube after the loading. Lysate solution $(100 \mu \mathrm{L})$ was added to each tube, incubated in ice for $30 \mathrm{~min}$, and shaken 3 times during the incubation. Centrifugation at $4{ }^{\circ} \mathrm{C}$ at $12000 \mathrm{RPM}$ for $15 \mathrm{~min}$ was performed, and the supernatant was placed in a new EP tube. The Bradford protein assay was used to determine the protein concentration, and the measurement system was used according to the instructions. After incubation for $4 \mathrm{~h}$ at $37^{\circ} \mathrm{C}$, plates were measured in a Microplate Reader (TECAN, Austria) at a wavelength of $450 \mathrm{~nm}$. 


\section{Cellular Physiology Cell Physiol Biochem 2017;42:441-454 and Biochemistry Published onIIne: IVlay 31, $2017 \quad$\begin{tabular}{l|l} 
DOI: 10.1159/000477592 2017 The Author(s). Published by S. Karger AG, Basel \\
www.karger.com/cpb
\end{tabular}}

Liu et al:: Overloaded Mechanical Stimulation Causes the Apoptosis of Osteoblasts

\section{LDH activity assays}

The supernatant from each culture group was used to measure the lactate dehydrogenase (LDH) activity. The OD value was measured on the Microplate Reader (TECAN, Austria) at a wavelength of $450 \mathrm{~nm}$.

\section{Intracellular calcium assays}

For the $1.5 \mathrm{~h}$ loading condition, $10 \mathrm{~mL}$ Fluo-4-am was added to the culture medium, and then the sample was loaded for $0.5 \mathrm{~h}$ in the dark. Cells were removed and placed in new EP tubes with Hank's medium and washed three times after loading. Then, $0.1 \%$ TritonX $(1 \mathrm{~mL})$ was added to each tube, which was shaken for $5 \mathrm{~min}$. Next, centrifugation at $12000 \mathrm{~g}$ for $5 \mathrm{~min}$ in $4{ }^{\circ} \mathrm{C}$ was performed. The supernatant was then removed $(100 \mu \mathrm{L})$ and placed in a 96-well black plate, which was measured in a fluorescence spectrophotometer using wavelengths of Ex/Em=488/506 nm.

\section{Extracellular ATP concentration assays}

After loading, $1 \mathrm{~mL}$ culture medium was removed (the medium was changed to Hank's medium before loading to evaluate the influence of N-ethylmaleimide (NEM) on the intracellular calcium concentration and the concentration of ATP at $1 \mathrm{~d}$ ). Centrifugation at $8000 \times \mathrm{g}$ was performed for $5 \mathrm{~min}$. The supernatant was removed $(100 \mu \mathrm{L})$ and placed in a white 96-well plate, ATP detection reagent was added, and the fluorescence was measured using a spectrophotometer.

Real-time quantitative PCR to measure the relative mRNA levels of Caspase-9, Caspase-3, Bcl-2 and Bax

Total RNA was extracted with Trizol (Invitrogen), and the RNA integrity was verified by denaturing agarose gel electrophoresis. The concentration of total RNA was determined using a Quant-iT RNA assay kit (Invitrogen). Reverse transcription was performed with $1 \mu \mathrm{g}$ RNA in a total volume of $20 \mu \mathrm{L}$ per reaction using Revertra Plus (Toyobo, KITA-KU, OSAKA, Japan). Quantitative RT-PCR was performed to determine the mRNA levels of Caspase-9, Caspase-3, Bax and Bcl-2 using a pair of primers specific to those genes (Table 1) on a Bio-Rad real-time PCR System (ABI, LA, CA, USA) with Brilliant SYBR Green master mix. The fold change was calculated using the control sample $C t$ values at each specified time point as a calibrator using the $2^{-\triangle \triangle C T}$ method. Three independent experiments were performed to determine relative mRNA levels.

Western blot to measure the protein expression of Caspase-9, Caspase-3, Bcl-2 and Bax

Cells were solubilized in modified RIPA buffer (1\% NP-40, 0.25\% sodium deoxycholate, $150 \mathrm{mM} \mathrm{NaCl}, 1$ mM EGTA, $1 \mathrm{mM}$ phenylmethyl-sulfonyl fluoride, $1 \mathrm{mg} / \mathrm{mL}$ aprotinin, leupeptin, pepstatin, and $1 \mathrm{mM}$ sodium ortho-vanadate in $50 \mathrm{mM}$ Tris- $\mathrm{HCl}, \mathrm{pH} 7.4$ ). Approximately $30 \mu \mathrm{g}$ protein was subjected to sodium dodecyl sulfate-polyacrylamide gel electrophoresis (SDS-PAGE) to determine the Caspase-9, Caspase-3, Bcl-2 and Bax expression. Subsequently, the proteins were transferred to nitrocellulose membranes. The membranes were blocked in TBS-T with $5 \%$ milk for $1 \mathrm{~h}$ and probed overnight at $4{ }^{\circ} \mathrm{C}$ with mouse anti-Caspase- 9 , mouse anti-Caspase-3 and anti-Bcl-2, anti-Bax antibodies (1:1000, Abcam, Cambridge, UK). After being washed, the membranes were incubated with HRP-conjugated secondary antibodies. The immunoreactive bands were visualized using an enhanced chemiluminescence detection kit. The optical density of the protein bands was determined with a Gel Doc 2000 (Bio-Rad, WA, CA, USA). The expression of GAPDH was used as a loading control. The results were presented relative to those of control cells without treatment.

\section{Statistical analysis}

All experiments were repeated at least three times, and values are expressed as the mean \pm standard deviation. All data were analyzed using one-way analysis to determine significant differences between groups using SPSS statistical software 21.0 (SPSS, Inc., Chicago, IL, USA). $P<0.05$ was considered to indicate a statistically significant difference.

Table 1. Oligonucleotides used in real-time PCR

\begin{tabular}{llc}
\hline \multicolumn{3}{c}{ Gene sequences of primers $\left(5^{\prime}-3^{\prime}\right)$ and primer length (bps) } \\
\hline Caspase-3 & F:TCTGACTGGAAAGCCGAAC & 68 \\
NM-009810.3 & R:GCAAGCCATCTCCTCACTA & \\
Caspase-9 & F:CCACTGCCTCATCATCAACA & 96 \\
NM-015733.5 & R:TCGTTCTTCACCTCCACCAT & \\
Bax & F:ATGCGTCCACCAAGAAGC & 126 \\
NM-007527.3 & R:CAGTTGAAGTTGCCATCAGC & \\
Bcl-2 & F:AGCCTGAGAGCAACCCAAT & 121 \\
NM-009741.5 & R:AGCGACGAGAGAAGTCATCC & \\
\hline
\end{tabular}




\section{Cellular Physiology and Biochemistry Published onlıne: May 31, $2017 \quad \begin{aligned} & \text { DOI: 10.1159/000477592 } 2017 \text { The Author(s). Published by S. Karger AG, Basel } \\ & \text { www.karger.com/cpb }\end{aligned}$ \\ Liu et al.: Overloaded Mechanical Stimulation Causes the Apoptosis of Osteoblasts}

\section{Results}

\section{Computer simulation for mechanical loading threshold}

We used ANSYS FEM analysis software (ANSYS, USA) for the residual analysis of the 300 $\mu \mathrm{m}$ fiber spacing of the 3-D printed PCL stent to determine the PCL strain distribution in the following mechanical loading conditions: $5000 \mu \varepsilon, 7500 \mu \varepsilon$ and $10000 \mu \varepsilon$. We found that with increasing mechanical stimulation, strain was enhanced on the fiber surface, and the strain scope of fibers at greater than $5000 \mu \varepsilon$ increased gradually. When the apparent strain reached $10000 \mu \varepsilon$, the strain scope of fiber at more than $4000 \mu \varepsilon$ would reach 60\% (Fig. 1). We chose an apparent strain of $10000 \mu \varepsilon$ for mechanical loading.

\section{Damage occurred with overloading for 8 days}

Fluorescence microscopy observation clearly showed that the control group nuclei were stained light blue by Hoechst-33342 solution (Fig. 2), and fewer nuclei were stained red by PI. The nuclear shape was roughly the same in the groups that were overloaded for $0.5 \mathrm{~h}$ for $8 \mathrm{~d}$ and $4 \mathrm{~d}$ and for $2 \mathrm{~h}$ for $4 \mathrm{~d}$ and in the control group; dead cells were less visible. This finding suggests that normal cultured cells did not undergo apoptosis. Shrinking nuclei were observed in the groups that were overloaded for $0.5 \mathrm{~h}$ for $12 \mathrm{~d}$ and $2 \mathrm{~h}$ for $8 \mathrm{~d}$ and 12

Fig. 1. Finite element analysis of a polycaprolactone (PCL) scaffold with $300-\mu \mathrm{m}$ strut spacing. Under an apparent strain of $10000 \mu \varepsilon$, the strut suffered $60 \%$ overloading; under an apparent strain of 7500 $\mu \varepsilon$, the strut suffered $48 \%$ overloading; and under an apparent strain of $5000 \mu \varepsilon$, the strut suffered $17 \%$ overloading.
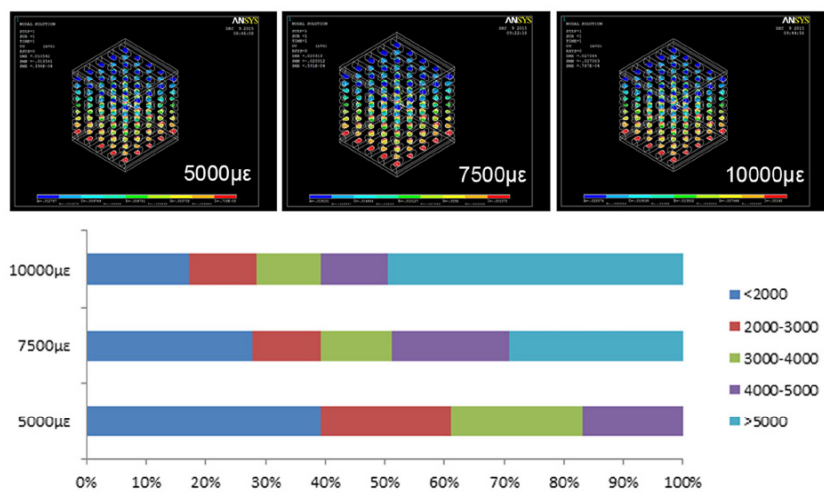

$<2000$

$2000-3000$

$>5000$

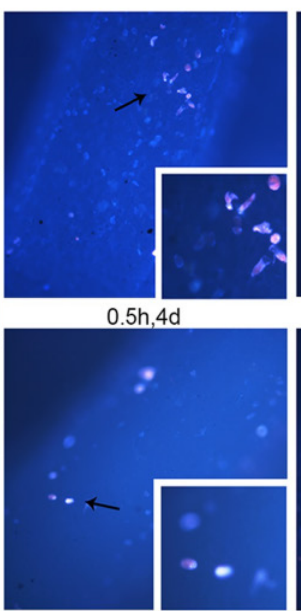

$2 \mathrm{~h}, 4 \mathrm{~d}$
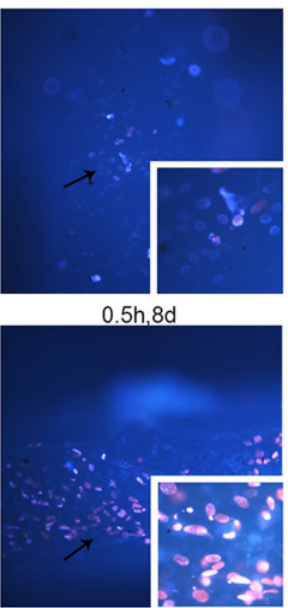

$2 h, 8 d$
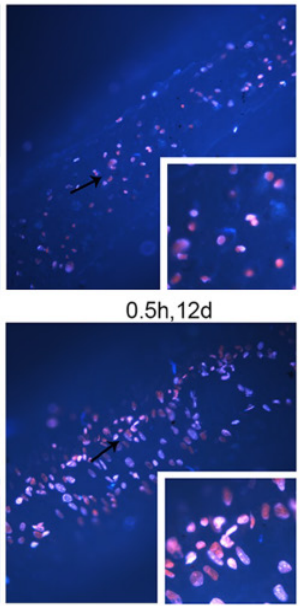

2h,12d

Fig. 2. Nuclei of control groups. Groups with overloading for $0.5 \mathrm{~h}$ for $4 \mathrm{~d}$ and $8 \mathrm{~d}$ and for $2 \mathrm{~h}$ for $4 \mathrm{~d}$ were stained light blue by Hoechst-33342 solution, and fewer nuclei were stained red by PI. Numerous cells were observed in the groups with overloading for $0.5 \mathrm{~h}$ for $12 \mathrm{~d}$ and for $2 \mathrm{~h}$ for $8 \mathrm{~d}$ and $12 \mathrm{~d}$; the cell shapes were irregular, and numerous apoptotic bodies were stained red by PI. 
d. The cell shapes were irregular, with numerous apoptotic bodies stained red by PI. This phenomenon proved that the apoptosis started at the overloading for $0.5 \mathrm{~h}$ every day for 12 days and 2 h every day for 8 days.

The CCK-8 value in the groups that were overloaded for $0.5 \mathrm{~h}$ for $4 \mathrm{~d}$ and $8 \mathrm{~d}$ or overloaded for $2 \mathrm{~h}$ for $4 \mathrm{~d}$ was significantly higher $(P<0.05)$ than in the normal control group (Fig. 3, A). With overloading $0.5 \mathrm{~h}$ for $12 \mathrm{~d}$ and overloading $2 \mathrm{~h}$ for $8 \mathrm{~d}$ and $12 \mathrm{~d}$, the OD value was significantly decreased $(P<0.05)$. This phenomenon suggests that loading for 4 days promoted cell proliferation and began to inhibit the proliferation at 8 days. With a duration less than 8 days, the OD value in the 0.5 -h group was greater than that of 2 -h groups $(P<0.05)$, and there was no significant difference $(P>0.05)$ between the overloading for $0.5 \mathrm{~h}$ and $2 \mathrm{~h}$

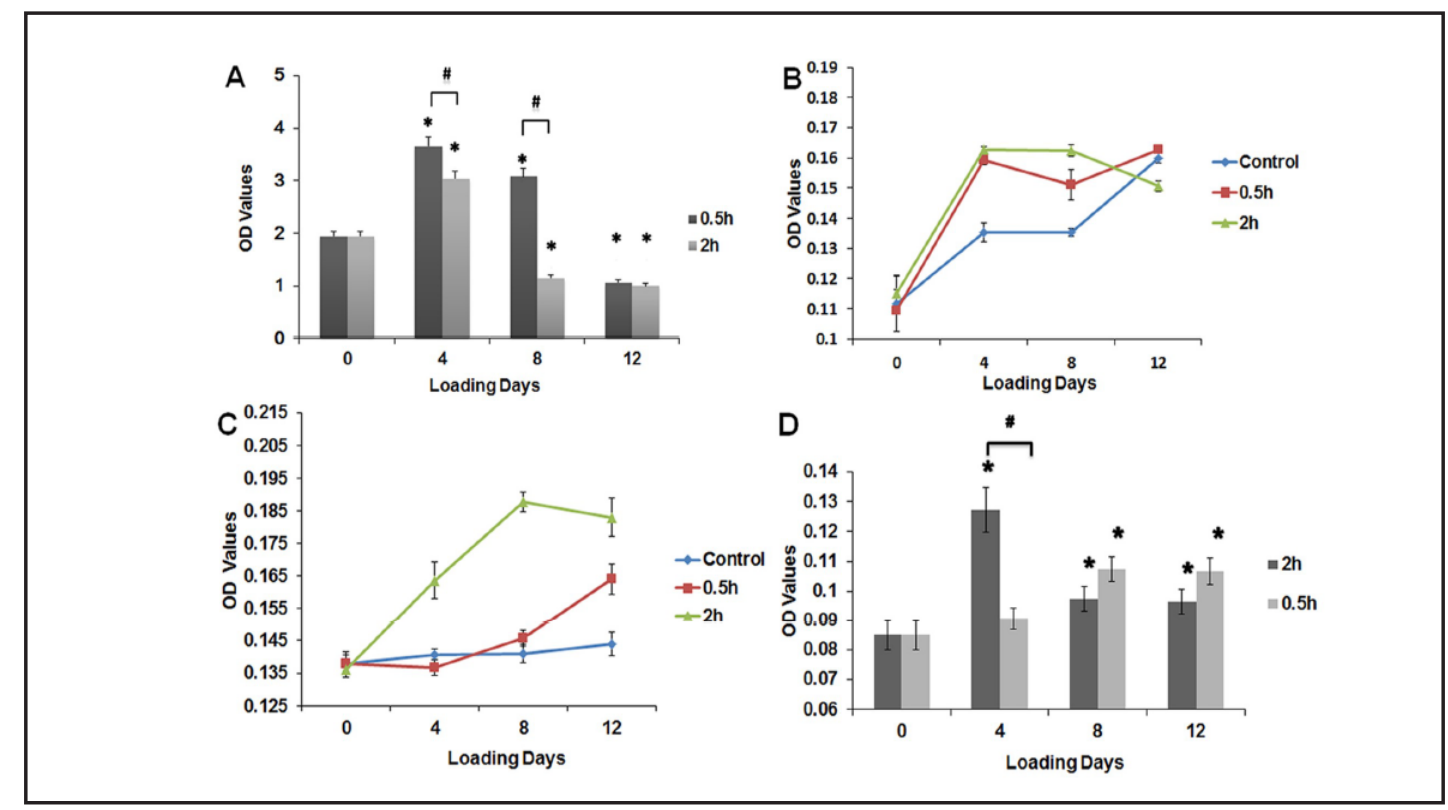

Fig. 3. The degree of damage to cells as a function of overloading duration and operation time was evaluated based on four experiments. The CCK-8 activity (A) increased initially and then decreased, and it was significantly reduced in the groups with overloading for $0.5 \mathrm{~h}$ for $8 \mathrm{~d}$ and $12 \mathrm{~d}$ and for $2 \mathrm{~h}$ for $12 \mathrm{~d}$ compared with the control group. The two groups of overloading, which were separated by operation time, showed significantly up-regulated AKP activity (B). The group with overloading for $0.5 \mathrm{~h}$ achieved the maximum value of LDH activity after overloading for $12 \mathrm{~d}(\mathrm{C})$, which was later than the time for the 2-h groups, in which the peak occurred at $8 \mathrm{~d}$. The Caspase- 3 activity was up-regulated in the $2 \mathrm{~h}$ for $4 \mathrm{~d}$ and $0.5 \mathrm{~h}$ for $8 \mathrm{~d}$ groups, with the value being highest in the former group (D). At $4 \mathrm{~d}$, the two groups showed the same effect. The results are shown as the mean \pm SD of data from three independent experiments. ${ }^{*} P<0.05$ versus controls, ${ }^{\#} P<0.05$ between groups.

Fig. 4. Overloading up-regulates the mRNA and protein expression of Caspase-3 and Caspase-9. The results are shown as the mean \pm SD of data from three independent experiments. * $P<0.05$ versus controls, ${ }^{\#} P<0.05$ between groups.

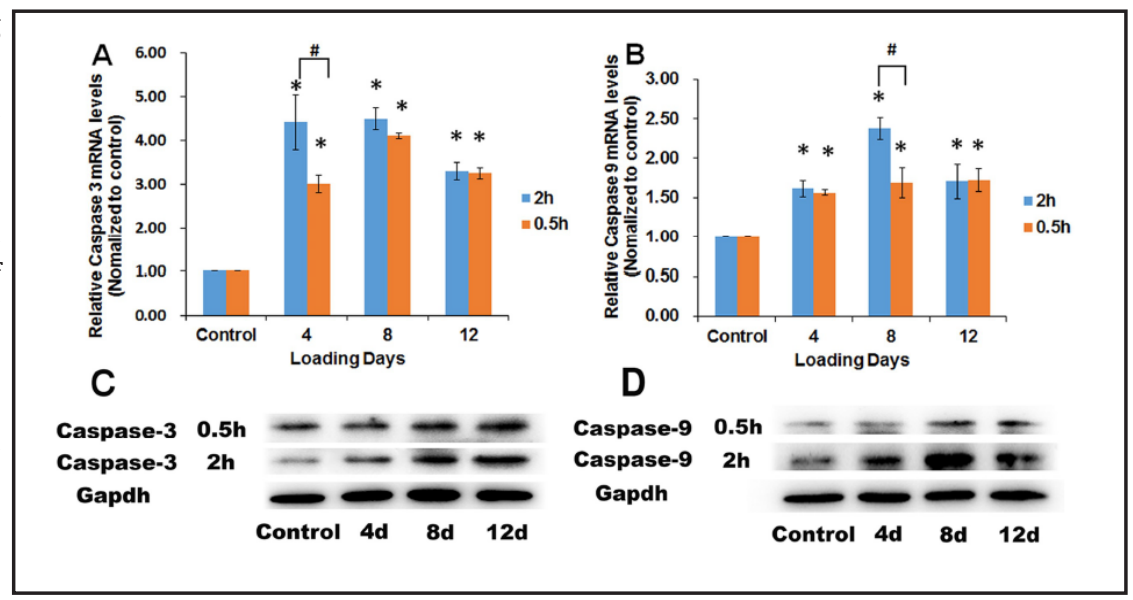


for $12 \mathrm{~d}$. This finding suggests that the inhibition of mechanical loading in the groups that were loaded for $2 \mathrm{~h}$ every day was obviously stronger than in the groups that were loaded for $0.5 \mathrm{~h}$. After overloading for 12 days, the cell proliferation in both groups was strongly inhibited.

The AKP activity in the control, 0.5 -h and 2-h groups was significantly different $(P<0.05)$, but there was no significant difference between the 0.5-h and 2-h groups $(P>0.05)$ (Fig. 3, B). This finding suggests that overloading can promote cell differentiation and is not related to the operation time. The AKP activity of the 4-d, 8-d, and 12-d groups was higher than that of the control group $(P<0.05)$, and there was no statistically significant difference between the 8-d and 4-d groups $(P>0.05)$. There was a significant interaction between operation time and duration $(P<0.05)$. This result suggests that a short period of overloading promoted osteoblast differentiation and a long period inhibited differentiation.

The rate of apoptosis can be reflected by the LDH activity. There was a significant difference $(P<0.05)$ between the LDH activity in the control group (Fig. $3, \mathrm{C})$ and that in the groups that were overloaded for $0.5 \mathrm{~h}$ or $2 \mathrm{~h}$ for 4,8 , and 12 days. The LDH activity was significantly higher in the groups that were loaded for $2 \mathrm{~h}$ than in those loaded for 0.5 $\mathrm{h}$ or the control group $(P<0.05)$. This finding suggests that the rate of apoptosis is faster for overloading for $2 \mathrm{~h}$ per day than for $0.5 \mathrm{~h}$ per day. There was an interaction between operation time (i.e., $0.5 \mathrm{~h}$ or $12 \mathrm{~h}$ ) and duration (i.e., 4 , 8, or 12$)(P<0.05)$, and the group that was loaded for $2 \mathrm{~h}$ per day for $8 \mathrm{~d}$ had the highest LDH activity. The results indicate that the rate of apoptosis reached the maximum in 8 days.

Compared with the value in the control group (Fig. 3, D), the Caspase-3 activity was increased $(P<0.05)$ in all groups except the group that was loaded for $0.5 \mathrm{~h}$ per day for 4 $\mathrm{d}$. This result suggests that overloading can promote the activation of genes related to cell apoptosis. The Caspase- 3 activity was significantly different $(P<0.05)$ between the groups that were loaded for $2 \mathrm{~h}$ and $0.5 \mathrm{~h}$ for $4 \mathrm{~d}$. However, there was no statistically significant difference between the two time points of loading for $8 \mathrm{~d}$ and $12 \mathrm{~d}(P>0.05)$. These results indicate that cells expressed apoptosis genes in response to overloading for $2 \mathrm{~h}$ per day for 4 $\mathrm{d}$, whereas the 0.5 -h group began to express apoptosis genes at $8 \mathrm{~d}$.

Compared with the value in the control group (Fig. 4), the gene expression of Caspase-9 and Caspase- 3 in the model group increased significantly $(P<0.05)$. The gene expression of Caspase- 3 with overloading for $2 \mathrm{~h}$ every day for $4 \mathrm{~d}$ was higher than that for the group with overloading for $0.5 \mathrm{~h}$ every day $(P<0.05)$. For Caspase-9, the group with overloading for 2 $\mathrm{h}$ every day for $4 \mathrm{~d}$ was higher than that of the group with overloading for $0.5 \mathrm{~h}$ every day $(P<0.05)$. This finding suggests that cells began to die at $4 \mathrm{~d}$ and that the effect of overloading for $2 \mathrm{~h}$ every day was significantly greater than that of overloading for $0.5 \mathrm{~h}(P<0.05)$. Western blot results showed that compared with the expression in the normal control group, the protein and mRNA expression of Caspase- 9 and Caspase- 3 in the model group increased significantly $(P<0.05)$. The protein expression in the group with overloading for $2 \mathrm{~h}$ every day was greater than that in the group with overloading for $0.5 \mathrm{~h}$. The results suggest that the expression of genes and proteins related to apoptosis was greater in the model group

Fig. 5. $\left[\mathrm{Ca}^{2+}\right]_{\mathrm{i}}$ and extracellular ATP concentration showed different trends with increasing duration of overloading. The $\left[\mathrm{Ca}^{2+}\right]_{\mathrm{i}}$ increased under overloading, except for at $4 \mathrm{~d}$ and peaked at $8 \mathrm{~d}$. Extracellular ATP levels were up-regulated at day 1 and down-regulated from day 3. The results are shown as the mean \pm SD of data from three independent experiments. ${ }^{* \#} P<0.05$ versus control groups.

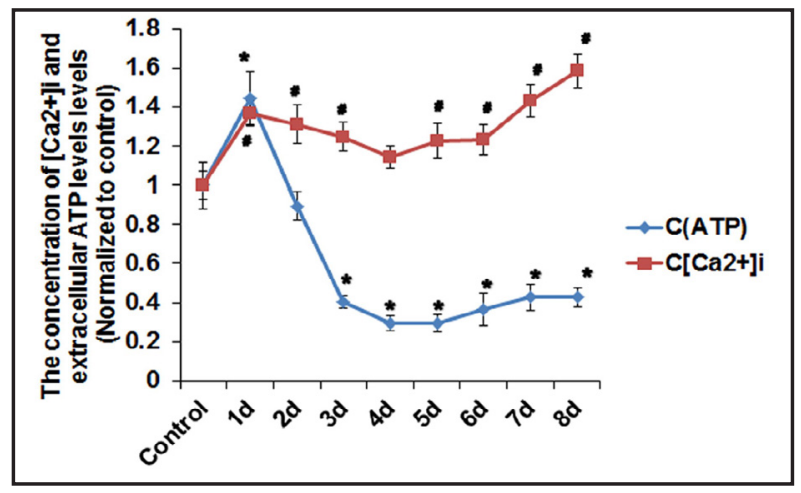


than in the control group. The longer cells were subjected to overloading, the higher the rate of apoptosis.

Different durations of overloading had different effects on extracellular ATP and intracellular calcium levels

Overloading for $2 \mathrm{~h}$ per day had different effects on the intracellular calcium and extracellular ATP levels for the different durations of overloading (Fig. 5). With increasing duration, the extracellular ATP content showed an initial increase, followed by a decrease. The concentrations of intracellular calcium and extracellular ATP increased significantly $(P<0.05)$ on the first day of overloading. On the second day, there was little difference in extracellular ATP between the control group and the model group $(P>0.05)$. The extracellular ATP concentration was significantly less than in the control group $(P<0.05)$ from the third day. This result suggests that the different biological effects on cells were related to the duration of overloading.

The extracellular ATP and intracellular calcium levels were significantly elevated by overloading for one day in Hank's medium (Fig. 6 A, B). NEM, a membrane fusion inhibitor that targets vesicles [22], significantly reduced this effect. This finding suggests that overloading promotes the release of ATP directly without a change in the calcium channels on the cell membrane to increase the intracellular calcium over a short duration. Compared with the model group, the group with verapamil had significantly lower extracellular ATP and intracellular calcium concentrations, which were up-regulated significantly by overloading $(P<0.05)$ (Fig. 6 C, D). This finding suggests that the ATP release induced by mechanical stimulation is dependent on the influx of calcium through calcium channels. These phenomena indicate that both the opening of calcium channels on the cell membrane and ATP secretion result in increased intracellular calcium in response to a short period of overloading.

Overloaded mechanical stimulation for 8 days (Fig. 7) significantly increased the intracellular calcium but decreased the extracellular ATP. Compared with the control group, the group that also received NEM had no significant difference in terms of the extracellular ATP or intracellular calcium concentrations $(P>0.05)$. However, compared with the control group, the group that also received verapamil had significantly lower extracellular ATP and

Fig. 6. Effect of NEM and verapamil on the $\left[\mathrm{Ca}^{2+}\right]_{\mathrm{i}}$ and extracellular ATP levels with overloading for 1 day. Overloading for 1 day up-regulated the $\left[\mathrm{Ca}^{2+}\right]_{\mathrm{i}}$ and extracellular ATP levels in Hank's medium. NEM significantly $(P<0.05)$ lowered the $\left[\mathrm{Ca}^{2+}\right]_{\mathrm{i}}$ and extracellular ATP levels in Hank's medium (A and B). Verapamil also significantly $(P<0.05)$ lowered the $\left[\mathrm{Ca}^{2+}\right]_{\mathrm{i}}$ and extracellular ATP levels (C and D).Verapamil and NEM both decreased the extracellular ATP and $\left[\mathrm{Ca}^{2+}\right]_{\mathrm{i}}$ compared with the values in the model group under overloading. The results are shown as the mean \pm SD of data from three independent experiments. ${ }^{*} P<0.05$ versus controls, ${ }^{\#} P<0.05$ versus model groups.

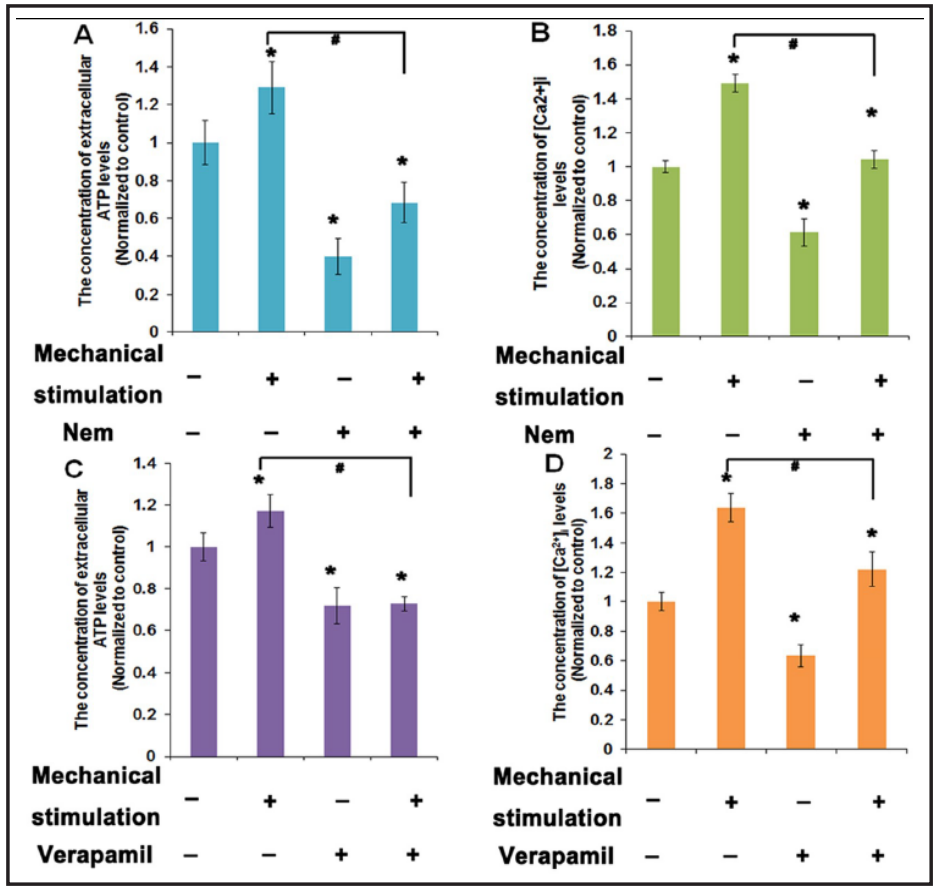


Fig. 7. Effects of NEM and verapamil on $\left[\mathrm{Ca}^{2+}\right]_{\mathrm{i}}$ and extracellular ATP levels with overloading for 8 days. Overloading for 8 days up-regulated the $\left[\mathrm{Ca}^{2+}\right]$ and decreased the level of extracellular ATP. NEM significantly $(P<0.05)$ lowered the $\left[\mathrm{Ca}^{2+}\right]_{\mathrm{i}}$ and extracellular ATP (A and B). Verapamil also significantly $(P<0.05)$ lowered $\left[\mathrm{Ca}^{2+}\right]_{i}$ and extracellular ATP (C and D). Verapamil decreased extracellular ATP and $\left[\mathrm{Ca}^{2+}\right]$ ${ }_{i}$ compared with the value in the model group, but NEM had no effect on these factors under overloading. The results are shown as the mean $\pm \mathrm{SD}$ of data from three independent experiments. * $P<0.05$ versus controls, ${ }^{*} P<0.05$ versus model groups.

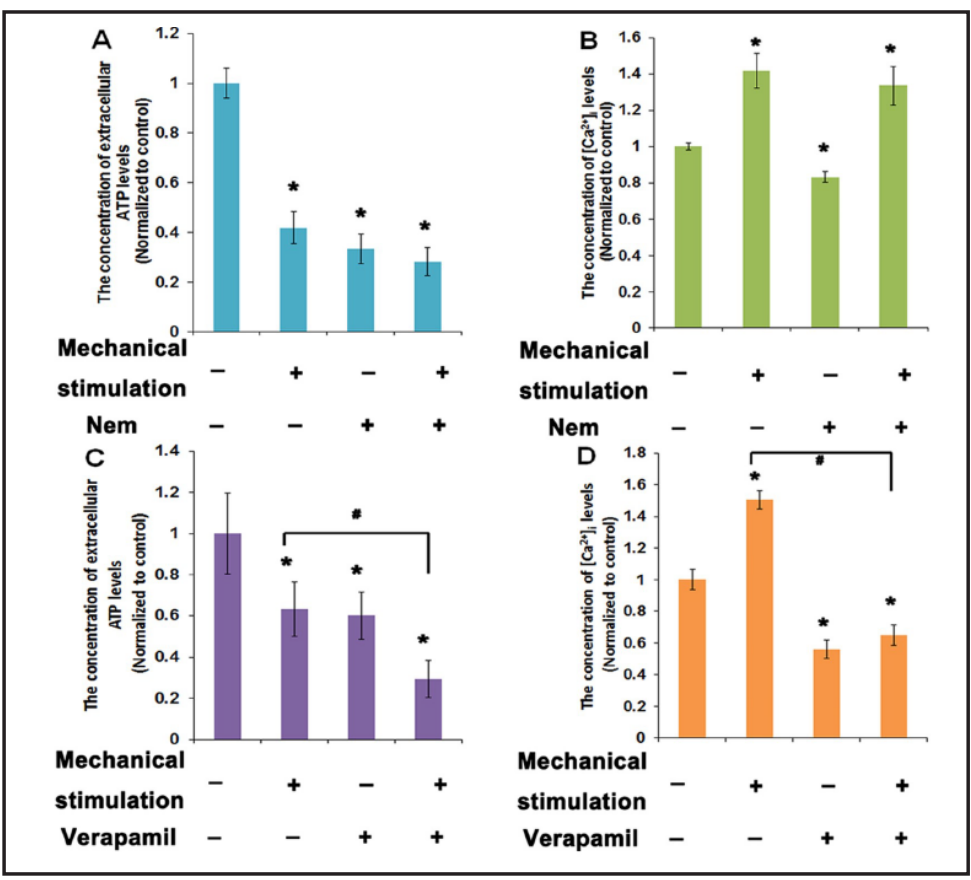

Fig. 8. Overloading up-regulated the mRNA (B, C, D) and protein (A) expression of Caspase-3, Caspase-9 and Bax/Bcl-2, but verapamil alone had no effect on these values. Compared with the model group, both the overloading groups and the verapamil group had lower mRNA and protein expression of Caspase-3, Caspase- 9 and $\mathrm{Bax} / \mathrm{Bcl}-2$. The results are shown as the mean \pm SD of data from three independent experiments. * $P<0.05$ versus controls, ${ }^{\#} P<0.05$ between groups.

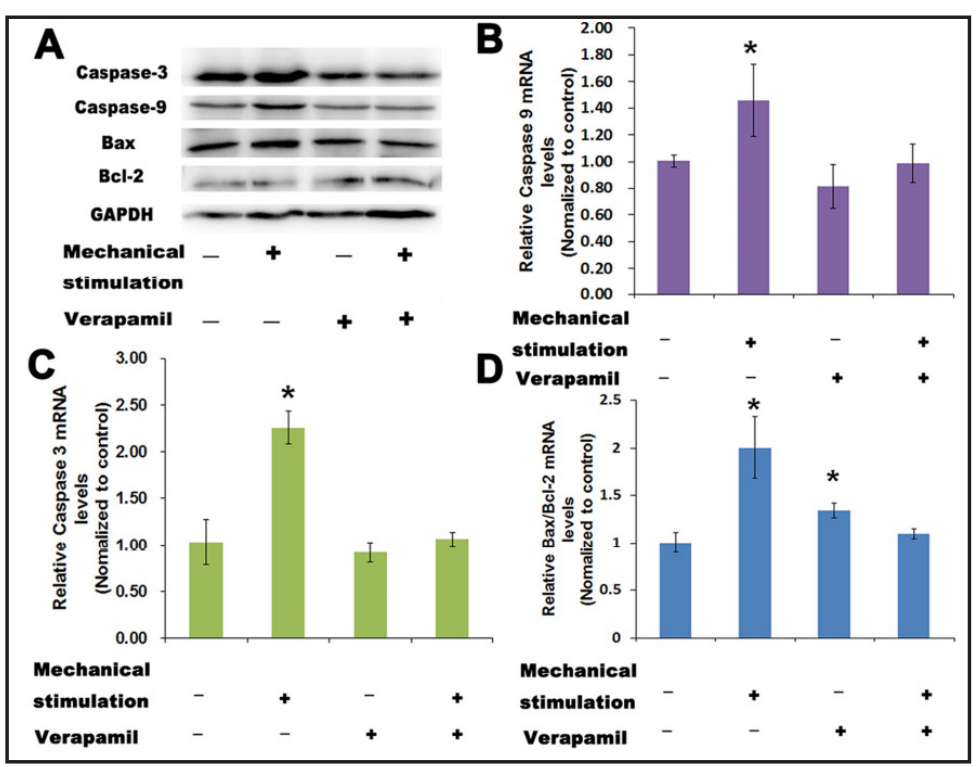

intracellular calcium concentrations, which were up-regulated by the overloaded mechanical stimulation $(P<0.05)$. This finding suggests that after overloading for 8 days, the relationship between the intracellular calcium concentration and the secretion of ATP had changed. The reduction of ATP secretion and its contribution to the increase in intracellular calcium was far less than the increase caused by the opening of membrane calcium channels.

To further explore the overloading-induced biological changes in cells (Fig. 8), we studied the effect of overloading for 8 days on the protein and mRNA expression of Caspase-3, Caspase- 9 and Bax/Bcl-2, all of which increased significantly in the model group compared with the normal group $(P<0.05)$. The addition of verapamil significantly decreased the expression of genes and proteins related to cell apoptosis in the overloading groups $(P<0.05)$ but not in normal cells. This result indicates that the calcium overload caused by the opening of calcium channels on the membrane led to cell apoptosis in $8 \mathrm{~d}$.

\section{KARGER}




\section{Cellular Physiology Cell Physiol Biochem 2017;42:441-454 \begin{tabular}{l|l} 
DOI: 10.1159/000477592 & O 2017 The Author(s). Published by S. Karger AG, Basel \\
www.karger.com/cpb
\end{tabular}}

Liu et al.: Overloaded Mechanical Stimulation Causes the Apoptosis of Osteoblasts

\section{Discussion}

Bone cells can sense mechanical stimulation and convert it into biochemical signals that lead to the expression of mechanically sensitive genes and proteins. The response of osteoblasts to mechanical stimulation depends on the type of mechanical stimulation. In studies of osteoblasts in recent years, the main applications of mechanical stimulation have been divided into fluid shear stress, cyclic stretching, and hydrostatic pressure [23]. The effect and mechanism of fluid shear stress and cyclic stretching on osteoblasts are relatively clear, but the effect of pressure on cells remains unclear. We explored the effect of pressure on cells using 3-D printed scaffolds in which the influence of the stress distribution is closer to that of humans.

It is well accepted that the physiological mechanical stimulation of bones increases osteoblast number and promotes the gene expression of differentiation markers, such as Col1 and Runx-2. This stimulation also enhances bone formation and the maintenance of healthy bone mass, thus preventing osteoporosis [24-29]. Physiological mechanical stimulation of long duration has no effect on osteoblasts $[30,31]$. This effect may be associated with bone matrix "strain resistance", which means a short operation time could lead the bone to adapt to mechanical stimulation.

Unlike physiological mechanical stimulation, we found that overloading had a 'Double effect' (Fig. 9). Overloading promoted cell proliferation, differentiation and apoptosis simultaneously. A short duration had a greater effect on osteoblast proliferation and differentiation. The number of cells increased in connection with a change in the expression of genes related to differentiation, which increased the bone mineral density. A long duration caused less proliferation and differentiation and promoted cell apoptosis, causing disorders of bone homeostasis and increasing the incidence of bone diseases related to fatigue damage [32-34]. We also found that with a short duration, the operation time did not affect the cell proliferation or differentiation. This point is consistent with the results from physiological mechanical stimulation. The degree of apoptosis was related to the operation time of overloading. Increasing the operation time increased the degree of cell apoptosis.

We found that the 'Double effect' on osteoblasts induced by overloading was related to the intracellular calcium concentration. Intracellular calcium is in dynamic homeostasis with the general environment [35]. Opening of calcium channels on the cell membrane increases intracellular calcium, causing highly repetitive spike-like $\left[\mathrm{Ca}^{2+}\right]_{\mathrm{i}}$ peaks under mechanical stimulation $[36,37]$. As a second messenger, calcium triggers a series of molecular biological

Fig. 9. Overloading had a 'Double effect' on osteoblasts. Calcium channel opening was induced by short-duration overloading and increasing intracellular calcium concentrations. At the same time, ATP release was induced by overloading and further increased the intracellular calcium concentration. This change promoted cell proliferation and differentiation. By contrast, long-duration overloading triggered cell apoptosis with increasing intracellular calcium concentration.

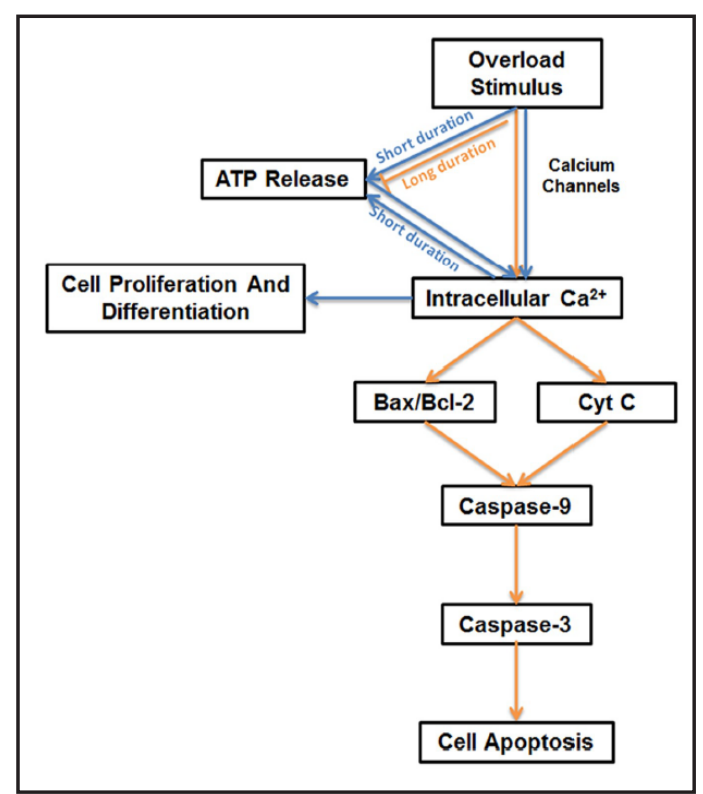




\section{Cellular Physiology Cell Physiol Biochem 2017;42:441-454

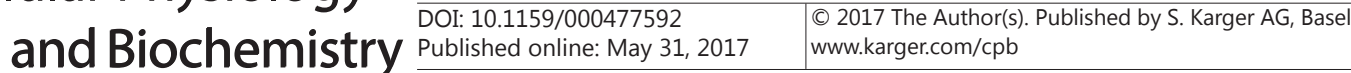

Liu et al.: Overloaded Mechanical Stimulation Causes the Apoptosis of Osteoblasts

effects and promotes cellular proliferation and differentiation. Calcium is removed by the $\mathrm{Ca}^{2+}$ pump on the cell membrane or stored in the endoplasmic reticulum to maintain calcium homeostasis [38]. An overload of intracellular calcium triggers cell apoptosis, with intracellular calcium concentrations increasing under long-duration overloading, under which the intracellular calcium cannot be readily removed from cells [39]. The results show that the intracellular calcium concentration increased significantly after the application of mechanical stimulation to cells. However, the addition of verapamil, a calcium channel inhibitor, significantly inhibited the increase in intracellular calcium. This finding clearly supported the mechanism in which calcium channels respond to overloading.

The increase in ATP secretion and in P2 receptors on the cell membrane induced by short-duration mechanical stimulation up-regulated calcium through the opening of calcium channels on the endoplasmic reticulum $[40,41]$. These effects promoted cell proliferation and differentiation. The results show that the trend was an initial increase in extracellular ATP [42], followed by a decrease with the application of mechanical stimulation. For the short duration, NEM [43] or verapamil decreased extracellular ATP significantly while also tending to reduce intracellular calcium levels. Two different subtypes of P2 receptors were involved in the extracellular ATP-dependent signaling. The P2X subtype receptors are $\mathrm{Ca}^{2+}$-permeable channels, and the cytosolic $\mathrm{Ca}^{2+}$ increase upon $\mathrm{P} 2 \mathrm{X}$ receptor activation is dependent on extracellular $\mathrm{Ca}^{2+}$. The P2Y subtype receptors are G-protein coupled receptors that activate phospholipase C (PLC), which generates IP3. IP3 induces $\mathrm{Ca}^{2+}$ release via IP3 receptors in the ER [44].

We also confirmed that mechanical stimulation can cause the opening of membrane calcium channels, thus contributing to the release of extracellular ATP. Our results shows that verapamil, an L-type voltage-sensitive $\mathrm{Ca}^{2+}$ channel (L-VSCC) blocker, could inhibit the release of extracellular ATP and the $\left[\mathrm{Ca}^{2+}\right]_{\mathrm{i}}$ increase, but how L-VSCCs are activated by mechanical perturbation is unclear [41]. Some studies reported that the release of ATP is associated with $\mathrm{Ca}^{2+}$-dependent vesicular exocytosis $[45,46]$. Only two channels have been shown to play a role in the $\left[\mathrm{Ca}^{2+}\right]_{\mathrm{i}}$ response to mechanical stimulation: the mechanosensitive cation-selective channel (MSCC) and VSCC [47]. MSCC is associated with prostaglandin, TGF $\beta$, and NO release [48], and the addition of $10 \mu \mathrm{M} \mathrm{GdCl}_{3}$, an MSCC blocker, did not significantly block ATP release [41]. However, a recent study showed that inhibition of VSCCs using either nifedipine or verapamil significantly reduced the bone formation in mechanically loaded rat tibias and ulnae in vivo, indicating the importance of this channel in mechanotransduction in bone [49]. Therefore, a cooperative relationship exists between the release of ATP and the opening of calcium channels on the membrane to promote the osteoblast proliferation and differentiation induced by short-term overloading.

Cells under long-duration overloading had a substantial reduction in ATP production and secretion. The addition of NEM had no effect on the calcium concentration. This finding indicates that ATP had little effect on elevating intracellular calcium. The intracellular calcium concentration was significantly lower and the expression of apoptosis genes and proteins was significantly decreased after the addition of verapamil. This result suggests that calcium channels that experienced long-duration overloading remained open on the cell membrane, which led to excessive intracellular calcium. Opening of the PTP channel on mitochondria is irreversible, the cytochrome $\mathrm{C}$ located in the mitochondrial membrane is released into the cytoplasm, and the gene and protein expression of Caspase- 9 and Caspase-3 induces cell apoptosis [50-51]. Therefore, one of the main factors causing cell apoptosis under overloading is the opening of calcium channels on the membrane rather than the release of ATP.

\section{Acknowledgments}

This work was supported by the Key Project of National Nature Science Foundation of China (Nos. 11432016, 11302262). 


\section{Cellular Physiology Cell Physiol Biochem 2017;42:441-454 and Biochemistry Published onlIne: IVay 31, $2017 \quad \begin{aligned} & \text { DOI: 10.1159/000477592 } 2017 \text { The Author(s). Published by S. Karger AG, Basel } \\ & \text { www.karger.com/cpb }\end{aligned}$}

Liu et al.: Overloaded Mechanical Stimulation Causes the Apoptosis of Osteoblasts

\section{Disclosure Statement}

The manuscript is original work that has not been submitted to and is not under consideration for publication by another journal. We confirm that all the listed authors have participated actively in the study and have seen and approved the submitted manuscript. The authors do not have any possible conflicts of interest.

\section{Reference}

1 Miller TL, Kaeding CC: Stress fractures in athletes. Orthopade 1997;26:961-971.

- 2 Bennell K L, Malcolm S A, Brukner P D, Green R M, Hopper J L, Wark J D, Ebeling P R: A 12-month prospective study of the relationship between stress fractures and bone turnover in athletes. Calcif Tissue Int 1998;63:8085.

3 Rodan GA: Mechanical loading, estrogen deficiency, and the coupling of bone formation to bone resorption. J Bone Miner Res 1991;6:527-530.

4 Bagi Č, Burger EH: Mechanical stimulation by intermittent compression stimulates sulfate incorporation and matrix mineralization in fetal mouse long-bone rudiments under serum-free conditions. Calcif Tissue Int 1989;45:342-347.

5 Guldberg RE, Caldwell NJ, Guo XE, Goulet RW, Hollister SJ, Goldstein SA: Mechanical stimulation of tissue repair in the hydraulic bone chamber. J Bone Miner Res 1997;12:1295-1302.

6 Giangregorio L, Blimkie CJ: Skeletal adaptations to alterations in weight-bearing activity: a comparison of models of disuse osteoporosis. Sports Med 2002;32:459-476.

7 Chamay A: Mechanical and morphological aspects of experimental overload and fatigue in bone. J Biomech 1970;3:263-264.

8 Wan ZM, Liu L, Li JY, Li RX, Guo Y, Li H, Zhang JM, Zhang XZ: Mechanical Stimulus Inhibits the Growth of a Bone Tissue Model Cultured In Vitro. Chin Med Sci J 2013;28:218-224.

-9 Orrenius S, Zhivotovsky B, Nicotera P: Regulation of cell death: the calcium-apoptosis link. Nat Rev Mol Cell Biol 2003;4:552-565.

10 Sun Z, Cao X, Zhang Z, Hu Z, Zhang L, Wang H, Zhou H, Li D, Zhang S, Xie M: Simulated microgravity inhibits L-type calcium channel currents partially by the up-regulation of miR-103 in MC3T3-E1 osteoblasts. Sci Rep 2015;5:8077, doi: 10.1038/srep08077.

11 Yang F, Yan G, Li Y, Han Z, Zhang L, Chen S, Feng C, Huang Q Ding F, Yu Y: Astragalus Polysaccharide Attenuated Iron Overload-Induced Dysfunction of Mesenchymal Stem Cells via Suppressing Mitochondrial ROS. Cell Physiol Biochem 2016;39:1369-1379.

12 Hu KH, Li WX, Sun MY, Zhang SB, Fan CX, Wu Q, Zhu W, Xu X: Cadmium Induced Apoptosis in MG63 Cells by Increasing ROS, Activation of p38 MAPK and Inhibition of ERK 1/2 Pathways. Cell Physiol Biochem 2015;36:642-654.

13 Zayzafoon M: Calcium/calmodulin signaling controls osteoblast growth and differentiation. J Cell Biochem 2006;97:56-70.

14 Matsui H, Fukuno N, Kanda Y, Kantoh Y, Chida T, Nagaura Y, Suzuki O, Nishitoh H, Takeda K, Ichijo H: The expression of Fn14 via mechanical stress-activated JNK contributes to apoptosis induction in osteoblasts. J Biol Chem 2014;289:6438-6450.

15 Rothenberg M: ATP signalling is crucial for the response of human keratinocytes to mechanical stimulation by hypo-osmotic shock. Exp Dermatol 2011;20:401-407.

-16 Sun D, Junger WG, Yuan C, Zhang W, Bao Y, Qin D, Wang C, Tan L, Qi B, Zhu D: Shockwaves induce osteogenic differentiation of human mesenchymal stem cells through ATP release and activation of P2X7 receptors. Stem Cells 2013;31:1170-1180.

17 Reigada D, Lu W, Zhang M, Mitchell CH: Elevated pressure triggers a physiological release of ATP from the retina: Possible role for pannexin hemichannels. Neuroscience 2008;157:396-404.

18 Sung KE, Su X, Berthier E, Pehlke C, Friedl A, Beebe DJ: Understanding the impact of 2D and 3D fibroblast cultures on in vitro breast cancer models. PLoS One 2013;8:e76373. 


\section{Cellular Physiology Cell Physiol Biochem 2017;42:441-454 \begin{tabular}{l|l} 
DOI: 10.1159/000477592 & O 2017 The Author(s). Published by S. Karger AG, Basel \\
www.karger.com/cpb
\end{tabular}}

Liu et al.: Overloaded Mechanical Stimulation Causes the Apoptosis of Osteoblasts

19 Kumar G, Tison CK, Chatterjee K, Pine PS, Mcdaniel JH, Salit ML, Young MF, Jr SC: The determination of stem cell fate by 3D scaffold structures through the control of cell shape. Biomaterials 2011;32:9188-9196.

20 Liu L, Shi G, Cui Y, Li H, Li Z, Zeng Q, Guo Y: Individual construction of freeform-fabricated polycaprolactone scaffolds for osteogenesis. Biomed Tech (Berl) 2017, doi:10.1515/bmt-2016-0005.

-21 Guo Y, Zhang CQ Zeng QC, Li RX, Liu L, Hao QX, Shi CH, Zhang XZ, Yan YX: Mechanical strain promotes osteoblast ECM formation and improves its osteoinductive potential. Biomed Eng Online 2012; doi. 10.1186/1475-925X-11-80.

-22 Whiteheart, Rossnagel, Buhrow, Brunner, Jaenicke: N-ethylmaleimide-sensitive fusion protein: a trimeric ATPase whose hydrolysis of ATP is required for membrane fusion. J Cell Biol 1994;126:945-954.

23 Ohashi T, Hanamura K, Azuma D, Sakamoto N, Sato M: Remodeling of Endothelial Cell Nucleus Exposed to Three Different Mechanical Stimuli. J Biomech Eng 2008;3:63-74.

24 Kang KS, Lee SJ, Lee HS, Moon W, Cho DW: Effects of combined mechanical stimulation on the proliferation and differentiation of pre-osteoblasts. Exp Mol Med 2011;43:367-373.

25 Li J, Fan Z, Chen JY: An integrated proteomics analysis of bone tissues in response to mechanical stimulation. BMC Syst Biol 2011;5:1-14.

26 Chow SK, Leung KS, Qin J, Guo A, Sun M, Qin L, Cheung WH: Mechanical stimulation enhanced estrogen receptor expression and callus formation in diaphyseal long bone fracture healing in ovariectomy-induced osteoporotic rats. Osteoporos Int 2016;27:2989-3000.

27 Klein-Nulend J, Bacabac RG, Bakker AD: Mechanical loading and how it affects bone cells: the role of the osteocyte cytoskeleton in maintaining our skeleton. Eur Cell Mater 2012;24:278-291.

28 Yumoto H, Hirao K, Tominaga T, Bando N, Takahashi K, Matsuo T: Electromagnetic wave irradiation promotes osteoblastic cell proliferation and up-regulates growth factors via activation of the ERK1/2 and p38 MAPK pathways. Cell Physiol Biochem 2015;35:601-615.

-29 Huang J, Peng J, Cao G, Lu S, Liu L, Li Z, Zhou M, Feng M, Shen H: Hypoxia-Induced MicroRNA-429 Promotes Differentiation of MC3T3-E1 Osteoblastic Cells by Mediating ZFPM2 Expression. Cell Physiol Biochem 2016;39:1177-1186.

-30 Boppart MD, Kimmel DB, Yee JA, Cullen DM: Time course of osteoblast appearance after in vivo mechanical loading. Bone 1998;23:409-415.

-31 Verbruggen S, Garrigle MM, Haugh M, Voisin M, Mcnamara L: Altered Mechanical Environment of Bone Cells in an Animal Model of Short- and Long-Term Osteoporosis. Biophys J 2015;108:1587-1598.

32 Hoshi K, Kawaki H, Takahashi I, Takeshita N, Seiryu M, Murshid SA, Masuda T, Anada T, Kato R, Kitaura H: Compressive Force-Produced CCN2 Induces Osteocyte Apoptosis Through ERK1/2 Pathway. J Bone Miner Res 2014;29:1244-1257.

33 Matsugaki A, Fujiwara N, Nakano T: Conditions for Osteoblast Arrangement Induced under Long-Term Cyclic Stretching. Materials Transactions 2013;54:1195-1199.

34 Weyts FA, Bosmans B, Niesing R, van Leeuwen JP, Weinans H: Mechanical control of human osteoblast apoptosis and proliferation in relation to differentiation. Calcif Tissue Int 2003;72:505-512.

-35 Jones DB, Nolte H, Scholübbers JG, Turner E, Veltel D: Biochemical signal transduction of mechanical strain in osteoblast-like cells. Biomaterials 1991;12:101-110.

-36 Smith MA, Schnellmann RG: Calpains, mitochondria, and apoptosis. Cardiovasc Res 2012;96:32-37.

-37 Lu XL, Huo B, Chiang V, Guo XE: Osteocytic network is more responsive in calcium signaling than osteoblastic network under fluid flow. J Bone Miner Res 2012;27:563-574.

-38 Fujimoto T: Calcium pump of the plasma membrane is localized in caveolae. J Cell Biol 1993;120:1147-1157.

-39 Hossain MM, Richardson JR: Mechanism of pyrethroid pesticide-induced apoptosis: role of calpain and the ER stress pathway. Toxicol Sci 2011;122:512-525.

40 Katz S, Boland R, Santillán G: Modulation of ERK 1/2 and p38 MAPK signaling pathways by ATP in osteoblasts: involvement of mechanical stress-activated calcium influx, PKC and Src activation. Int J Biochem Cell Biol 2006;38:2082-2091.

41 Genetos DC, Geist DJ, Liu D, Donahue HJ, Duncan RL: Fluid Shear-Induced ATP Secretion Mediates Prostaglandin Release in MC3T3-E1 Osteoblasts. J Bone Miner Res 2005;20:41-49.

\$2 Orriss IR, Knight GE, Utting JC, Taylor SE, Burnstock G, Arnett TR: Hypoxia stimulates vesicular ATP release from rat osteoblasts. J Cell Physiol 2009;220:155-162.

-43 Stenmark KR, Yeager ME, Kasmi KCE, Nozikgrayck E, Gerasimovskaya EV, Li M, Riddle SR, Frid MG: The Adventitia: Essential Regulator of Vascular Wall Structure and Function. Annu Rev Physiol 2012;75:23-47. 


\section{Cellular Physiology Cell Physiol Biochem 2017;42:441-454

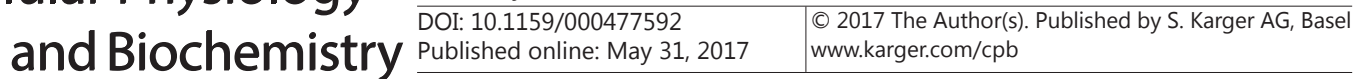

Liu et al.: Overloaded Mechanical Stimulation Causes the Apoptosis of Osteoblasts

44 Ryu SY, Peixoto PM, Won JH, Yule DI, Kinnally KW: Extracellular ATP and P2Y2 receptors mediate intercellular $\mathrm{Ca} 2+$ waves induced by mechanical stimulation in submandibular gland cells: role of mitochondrial regulation of store operated Ca2+ entry. Cell Calcium 2010;47:65-76.

45 Tatur S, Groulx N, Orlov SN, Grygorczyk R: Ca2+-dependent ATP release from A549 cells involves synergistic autocrine stimulation by coreleased uridine nucleotides. J Physiol 2007;584:419-435.

$\$ 46$ Knight GE, Bodin P, De Groat WC, Burnstock G: ATP is released from guinea pig ureter epithelium on distension. Am J Physiol Renal Physiol 2002;282:F281-288.

47 Hung CT, Allen FD, Pollack SR, Brighton CT: Intracellular Ca2+ stores and extracellular Ca2+ are required in the real-time Ca2+ response of bone cells experiencing fluid flow. J Biomech 1996;29:1411-1417.

48 Sakai K, Mohtai M, Iwamoto Y: Fluid shear stress increases transforming growth factor beta 1 expression in human osteoblast-like cells: modulation by cation channel blockades. Calcif Tissue Int 1998;63:515-520.

49 Li J, Duncan RL, Burr DB, Turner CH: L-type calcium channels mediate mechanically induced bone formation in vivo. J Bone Miner Res 2002;17:1795-1800.

50 Szalai G, Krishnamurthy R, Hajnóczky G: Apoptosis driven by IP3-linked mitochondrial calcium signals. EMBO J 1999;18:6349-6361.

51 Liu R, Fu C, Sun J, Wang X, Geng S, Wang X, Zou J, Bi Z, Yang C: A New Perspective for Osteosarcoma Therapy: Proteasome Inhibition by MLN9708/2238 Successfully Induces Apoptosis and Cell Cycle Arrest and Attenuates the Invasion Ability of Osteosarcoma Cells in Vitro. Cell Physiol Biochem 2017;41:451-465. 